\title{
Uma contribuição da educação ambiental crítica para (des)construção do olhar sobre a seca no semiárido baiano
}

\author{
A contribution of critical environmental education \\ for constructing new views on the drought \\ in the Bahia area of semiarid Brazil
}

\author{
Lakshmi Juliane Vallim Hofstatter $^{1}$ • Haydée Torres de Oliveira ${ }^{2}$. \\ Francisco José Bezerra Souto ${ }^{3}$
}

\begin{abstract}
Resumo: A seca nordestina vem produzindo, ao longo de séculos, muitos estereótipos que se plasmam em diferentes percepções, que nos motivaram a buscar uma melhor compreensão sobre este fenômeno. Trabalhamos com professoras/es de uma escola municipal localizada na comunidade de Brejo dos Olhos d’Água, semiárido baiano. Os dados foram coletados durante um processo de formação em educação ambiental, na perspectiva crítica, pautados em metodologias participativas. Utilizamos questionários, grupo focal e o método de foto-elicitação, ancorando a análise na hermenêutica. Traçamos um panorama do processo social na constituição da percepção sobre a seca, constatando algumas heranças históricas que influenciam na forma como as pessoas vivem e percebem seu meio. Evidenciou-se a necessidade de investimento na formação continuada e contextualizada de professoras/es, pois muitas/os ainda reproduzem discursos propagados historicamente pela mídia e literatura, às vezes equivocados. Constatamos que a interação educacional contribui para a compreensão deste fenômeno e pode criar condições para a (re)construção destes olhares.
\end{abstract}

Palavras-chave: Educação ambiental. Seca. Formação de professores. Região nordeste.

Abstract: For centuries, the drought in northeast Brazil has produced many stereotypes resulting in different perceptions of people, which lead us to search for a better understanding about this phenomenon. We investigated the work of teachers in a municipal school located in the community "Brejo dos Olhos d'Água" in semi-arid area of northeast Brazil. Data were collected during a course process of environmental education, in a critical perspective, based on participatory methodologies. We used questionnaires, focus groups and a photo-elicitation method, which were analyzed through a hermeneutic approach. We outlined a panorama of social process, which was made up of the participants' perceptions of the drought, noting some historical and political background that directly influences the way people live and perceive their environment. We believe that the lack of investment in a continuing and contextualized training for teachers was apparent; since many of them still reproduce discourses historically propagated by the media and misguided literature.

Key-words: Environmental education. Drought. Teachers' training.

\footnotetext{
${ }^{1}$ Universidade Federal de São Carlos (UFSCar), Programa de Pós-graduação em Ecologia e Recursos Naturais, São Carlos, SP, Brasil. E-mail: <lakshmivallim@hotmail.com>.

${ }^{2}$ Universidade Federal de São Carlos (UFSCar), Departamento de Ciências Ambientais, São Carlos, SP, Brasil.

${ }^{3}$ Universidade Estadual de Feira de Santana (UEFS), Departamento de Ciências Biológicas, Laboratório de Etnobiologia e Etnoecologia, Feira de Santana, BA, Brasil.
} 


\section{Introdução}

A educação ambiental não deve se restringir aos espaços formais de educação, porém é preciso considerar a relevância de sua ocorrência nestes espaços. Se a maior finalidade da escola deveria ser a de promover uma educação comprometida com a formação integral de estudantes, é muito importante a inserção da dimensão ambiental para que as pessoas possam pensar e perceber o mundo de forma crítica e vivê-lo de maneira mais justa, equilibrada e equitativa em relação aos recursos naturais.

As professoras/es, no exercício de suas práticas, lidam diariamente com a formação de crianças e jovens, que são o reflexo do que a sociedade pode vir a ser. Porém, existe uma deficiência muito grande em relação aos assuntos socioambientais na formação em cursos de licenciatura (incluindo a Pedagogia), bem como nos demais cursos superiores. Assim, não há preparo suficiente das/os professoras/es para lidar com esses assuntos, o que acarreta em perda para a sociedade como um todo. Por esse motivo escolhemos desenvolver esse trabalho com um curso para professoras/es que atuam no semiárido.

Conforme argumentam Oliveira, Farias e Pavesi (2008), as instituições de ensino superior são importantes espaços sociais para reflexão, formação e difusão de novas concepções de desenvolvimento e sustentabilidade. É importante a formação de licenciadas/os enquanto estratégia de ambientalização do ensino na sociedade. Como destacam Barbosa, Silva e Nascimento (2011, p. 411), “[...] a ausência da inserção da temática ambiental dos currículos da escola compreende um entrave a tão sonhada sustentabilidade”. E ainda, segundo Oliveira et al. (2000, p. 1) "[...] a temática ambiental emerge como uma possibilidade fecunda de engajamento de professores e alunos em situações de ensino-aprendizagem, nas quais a problematização tem sido facilmente atingida, por envolver direta ou indiretamente, questões vitais".

Por estes e outros fatores defendemos a garantia de formação socioambiental de professoras/es em exercício, principalmente estando em um bioma historicamente desvalorizado. A caatinga foi descrita por muito tempo, na literatura, como um bioma pobre em termos de biodiversidade (CASTELLETTTI et al., 2003). Além disto, a mídia, os materiais didáticos e as políticas públicas, ainda hoje, não contribuem para ruptura da imagem negativa e estereotipada do semiárido e de sua população.

É importante ressaltar que o bioma caatinga não é homogêneo e apresenta muitas variações, marcadas principalmente pela drenagem de rios como o São Francisco, entre outros, e por serras e chapadas, deixando o clima local mais úmido (ANDRADE, 1988). Estas são as áreas conhecidas como "brejos", justamente o tipo de caatinga trabalhado nesta pesquisa. Uma característica comum a todo bioma é estar em um ambiente onde a principal questão socioambiental se relaciona ao regime hídrico, afetando diretamente a produção de alimentos, a manutenção dos animais de criação e, por consequência, a sobrevivência direta de seus habitantes, inclusive nas áreas brejeiras que são privilegiadas em relação às demais.

Quando analisamos a seca de maneira holística, extrapolando as "adversidades ambientais" e, inserida em historicidade, torna-se possível compreender a complexidade da teia

\footnotetext{
${ }^{4}$ Adotamos linguagem não sexista.
} 
de relações que se estabelece, refletindo na estruturação social. Gomes (1998, p. 93) diferencia a estiagem como aspecto natural e a seca como aspecto social, de forma que "a estiagem seria a forma físico-climatológica de expressão do movimento da natureza e a seca, o conjunto de significações sociais construídas pelos diversos estratos sociais de interesse".

Empossados deste entendimento, procuramos destrinchar as faces de constituição desta estruturação social, através da percepção ambiental de professoras/es que vivem e (se) educam no semiárido. Entender as percepções em um processo educacional exigiu uma atenção tanto sobre a formação de professoras/es proposta, como na coleta de dados para desvelar a essência do que as pessoas vivem neste ambiente. Buscamos ler e interpretar o meio, coletivamente, pelos contextos naturais, culturais, históricos, sociais, educacionais e políticos. E, ao mesmo tempo em que procurávamos entender como se davam as relações socioambientais locais, suscitávamos, também, reflexões coletivas e individuais.

Essa formação em educação ambiental se insere na perspectiva crítica (SAUVÉ, 2005; SORRENTINO, 2002), dentre as diversas linhas que a educação ambiental assume. Nesta vertente, Carvalho (2008) argumenta que devem ocorrer processos de formação do sujeito humano que instituam novos modos de ser, de compreender e posicionar-se ante os outros e a si mesmo, enfrentando os desafios e as crises do tempo que vivemos. Para Carvalho (2008, p. 156-157), “o projeto político pedagógico de uma EA crítica poderia ser sintetizado na intenção de contribuir para uma mudança de valores e atitudes, formando um sujeito ecológico capaz de identificar e problematizar as questões socioambientais e agir sobre elas".

Outro pressuposto para pensarmos esta educação ambiental crítica, apropriada à realidade da caatinga, também se fundamenta na educação contextualizada, inserida na perspectiva de educação popular proposta por Paulo Freire. Como expõem Silva e Silva (2010, p. 216) "transformar o contexto em um elemento desencadeador da aprendizagem e do entendimento da complexidade humana é função da Educação Contextualizada". Portanto, a educação contextualizada pode promover uma produção de conhecimento apropriada a cada realidade social, considerando a diversidade cultural (TAVARES, 2009). Sustentamos que a educação envolve relações cognitivas complexas que requerem além de um corpo substancial de conhecimentos e habilidades, a necessidade de criatividade e o comprometimento em traduzir o processo educativo ao contexto vivido para torná-lo significativo (LABURÚ; ARRUDA; NARDI, 2003).

Também optamos por pensar e praticar a educação pela transdisciplinaridade, com o entendimento da/o estudante enquanto um ser com múltiplas dimensões; e da escola enquanto um elo social que se relaciona com um sistema maior, também complexo. Além disso, sua adoção nos permitiu conceber a formação de professoras/es em diferentes linguagens, como a fotográfica, além da vivência e discussão dos temas de maneira transversal e holística.

A transdisciplinaridade é uma abordagem cada vez mais difundida, porém a forma setorizada como as escolas e as pessoas ainda se organizam, a regência disciplinar e a estrutura do sistema escolar dificultam uma implantação efetiva de sua elaboração teórica (OLIVEIRA; ZANCUL, 2011). Como afirmam Thiesen (2008) e Santos (2008), a transdisciplinaridade e a interdisciplinaridade envolvem mudanças paradigmáticas e um pensamento multidimensional capaz de ler e compreender a complexidade.

De fato, a abordagem transdisciplinar tem sido uma das formas de superação da lógica cartesiana e da fragmentação tanto dos seres humanos nos aspectos racionais, afetivos e subjetivos, como dos saberes em disciplinas. Para tal, propõe-se uma aproximação de diferentes 
campos de conhecimentos, procurando uma axiomática comum entre ciências, arte, filosofia, religião e conhecimentos tradicionais (OLIVEIRA, 2005). Além disso, a transdisciplinaridade opera em torno da democracia cognitiva, em que todos os saberes são igualmente importantes, buscando superar suas hierarquizações (SANTOS, 2008).

\section{Desenvolvimento metodológico}

\section{Localização da comunidade e da Escola Municipal Espírito Santo}

A comunidade do Brejo dos Olhos d'Água está localizada no município de Barra, ao oeste do estado da Bahia, na região do Baixo-Médio São Francisco, na APA Dunas e Veredas do Baixo-Médio São Francisco. Segundo o censo IBGE de 2010, Barra possui cerca de 49 mil habitantes, dos quais 54,5\% vivem na zona rural. Destes, 16 mil vivem na região de brejos da Barra conforme dados do IBGE 2002 (SOUSA SOBRINHO, 2006). De acordo com o referido autor, "nas estreitas planícies das vazantes que margeiam os cursos d água e lagoas estão instaladas as comunidades brejeiras, que praticam nessas áreas culturas de subsistência e criatórios soltos nas extensas áreas de caatinga” (SOUSA SOBRINHO, 2006, p. 169-170).

A Escola Municipal Espírito Santo de ensino fundamental possui uma boa estrutura física com salas organizadas, banheiros e pátio bem cuidados, uma realidade bem diferente de boa parte das escolas do sertão, atendendo estudantes entre 4 e 19 anos, pois muitos são repetentes ou retornaram à escola após um tempo de evasão.

\section{Grupo participante e coleta de dados}

O grupo foi constituído por 25 pessoas, sendo 19 professoras/es e seis integrantes da comunidade, que tiveram interesse em participar. A distribuição por gênero foi quase equitativa, sendo 14 participantes do sexo masculino e 11 do feminino. A formação superior das/ os professoras/es é nas áreas de letras, pedagogia e história, que são os cursos oferecidos na região e um participante possui formação técnica em meio ambiente. Estas/es professoras/es residem na própria comunidade ou nas comunidades vizinhas.

A turma foi convidada, desde o primeiro encontro com a primeira autora, a construírem o conhecimento de forma participativa e coletiva. Entre setembro de 2012 e março de 2013, houve quatro encontros de formação com uma média de 20 participantes. Os dados foram coletados através de observações de campo, de práticas participativas propostas, por questionários aplicados e com uma entrevista coletiva em formato de grupo focal. Todas as discussões ocorridas durante as atividades foram gravadas em áudio, com o consentimento do grupo, após esclarecimento sobre os objetivos da pesquisa e comprometimento na devolução e discussão dos resultados gerados.

\section{Caminho metodológico percorrido}

Propusemos que, através de práticas dialógicas, a educação se desenvolvesse pautada em valores propagados por Freire (2003) como a autonomia, a valorização da pluralidade de 
culturas, na perspectiva de promover emancipação educacional e política. Esta pesquisa qualitativa caminhou juntamente a um processo formativo tanto na coleta como na análise de dados. Percorremos um caminho interpretativo no qual os dados não existem de forma independente, ou seja, são produzidos pelo grupo participante e pela pesquisadora nos momentos de seus encontros, o que é fundamental para realizar interpretações em que os sujeitos se identifiquem (BANKS, 2009). Como definido por Oliveira (2007, p. 37), trata-se de "um processo de reflexão e análise da realidade através da utilização de métodos e técnicas para compreensão detalhada do objeto de seu estudo em seu contexto histórico e/ou segundo a sua estruturação”.

Adotamos também alguns preceitos da pesquisa qualitativa descritos por Godoy (1995), dentro os quais, que o ambiente natural é uma fonte direta de dados. Desta forma, "um fenômeno pode ser mais bem observado e compreendido no contexto em que ocorre e do qual é parte". Outro preceito importante é o significado que as pessoas dão às coisas e às suas vidas e, portanto, "os pesquisadores qualitativos tentam compreender os fenômenos que estão sendo estudados a partir da perspectiva dos participantes" (GODOY, 1995, p. 62-63).

A coleta de dados ocorreu em diferentes momentos durante o curso de formação e se deu no âmbito de uma pesquisa mais ampla, que abordou aspectos como a percepção sobre a seca e a caatinga, sentidos atribuídos à convivência com as onças e utilização didática da fotografia enquanto modo conhecedor do ambiente (HOFST'TATER, 2013). Para tanto, envolveu as metodologias participativas, tais como a construção de biomapas, elaboração de conceitos socioambientais, tomadas fotográficas e rodas de conversa.

Os dados e o aprendizado se constituíram tanto da execução e dos resultados das atividades, como das reflexões oriundas dos momentos em que dialogávamos sobre os temas tratados. No primeiro dia de encontro, foi aplicado um questionário para compreendermos um pouco de como as/os participantes compreendiam de seu meio ambiente e alguns aspectos naturais de seu entorno. Utilizamos, no terceiro encontro, a produção de fotografias pelo método de foto-elicitação (BANKS, 2009). E, no último encontro com o grupo, fizemos uma entrevista coletiva, no formato de grupo focal, que teve por objetivo melhor esclarecer algumas questões que se delinearam durante o transcorrer de todo o trabalho.

Para a aplicação do método de foto-elicitação, as fotos poderiam ser escolhidas previamente, mas optamos em de pedir que os sujeitos criassem suas próprias imagens. Nesta escolha, além de uma maior participação, foram revelados aspectos de vidas e de interações humanas com o ambiente que não estariam disponíveis de outra forma. Também se desenvolveu uma aproximação com a natureza, pois, como argumenta Farnsworth (2011), vivenciaram a comunidade de forma diferente das cotidianas. Além disso, a produção de imagens possibilitou sua experimentação enquanto forma de representação e comunicação, podendo servir como recurso didático em suas atuações profissionais, se assim desejarem.

Antes da saída para a prática fotográfica, foi feita uma aula expositiva dialogada introduzindo questões sobre técnicas fotográficas, enfocando que, neste caso, um breve conhecimento da técnica poderia auxiliar no uso da fotografia enquanto meio de comunicação. Formaram-se, então, quatro grupos em agrupamento livre para que saíssem pelo espaço ao redor da escola e pela comunidade de Brejo dos Olhos d'Água para fotografarem aspectos que refletissem o que fosse socioambientalmente importante para eles.

Depois da saída, voltamos à escola e cada grupo apresentou suas imagens. Solicitamos que compartilhassem o que pretendiam mostrar através delas e o que era significativo nas 
mesmas. De acordo com o método adotado, as fotografias são utilizadas para gerar discussões, evocar memórias e comentários (BANKS, 2009; IARED; DI TULLIO; OLIVEIRA, 2012), na medida em que, de modo geral, as fotografias têm uma alta qualidade icônica, podendo ativar memórias e auxiliar na elaboração de enunciados sobre situações e processos complexos (FLICK, 2009). Essa atividade foi conduzida e direcionada em alguns momentos, quando se percebia a importância do assunto para o grupo. A apresentação foi gravada em áudio, o que permitiu uma verificação posterior dos comentários gerados bem como a excitação do grupo perante algumas temáticas. Ao final da atividade, fizemos uma avaliação dialogada sobre as possibilidades pedagógicas e de ensino através da fotografia.

Utilizamos a hermenêutica no ato de interpretar o teor subjetivo durante o processo conhecedor e de desvelamento do que está implícito no explícito (FLICK, 2009; HERMANN, 2002; PENN, 2010). Para isso, foi fundamental o entendimento entre os sujeitos participantes e a pesquisadora através de práticas dialógicas conforme a concepção de Freire (2012) e Gadamer (2012, p. 38) que defende que "um diálogo frutífero é um diálogo no qual oferecer e acolher conduzem, por fim, a algo que se mostra como um sítio comum com o qual estamos familiarizados e no qual podemos nos movimentar uns com os outros".

Ao longo das discussões, inserimos informações da literatura sobre a seca para melhor subsidiar as práticas dialógicas, pois a proposta do curso foi de uma construção participativa do saber. Assim, o conhecimento era partilhado trazendo novos elementos reflexivos e fatos históricos que eram desconhecidos por grande parte do grupo.

\section{Dialogando com os resultados}

Como a coleta dos dados se deu no âmbito de uma pesquisa mais ampla, os resultados aqui apresentados referem-se a um recorte específico, ou seja, a (des)construção do olhar sobre a seca. Desta forma, apresentamos as fotografias que reportam à esta questão. Além disso, utilizamos as falas transcritas sobre o que foi discutido em sala de aula durante a apresentação destas fotos. Também trabalhamos com os dados das respostas contidas no questionário aplicado e com as falas obtidas e transcritas junto ao grupo focal. Optamos por não identificar as/os participantes e manter as falas o mais próximo do que foi dito ou escrito, modificando apenas os aspectos que pudessem comprometer o entendimento do conteúdo.

A análise do conjunto destes dados, respaldados pela revisão bibliográfica, permitiu uma inferência e um agrupamento em diferentes categorias de influência, apresentados a seguir. Ainda que possam ser tema de aprofundamento, as categorias são apresentadas brevemente, e de forma separada, para melhor compreender os fatores que compõem o entendimento das/ os participantes. No entanto, são aspectos totalmente imbricados e que, em seu conjunto interatuante, constituem os olhares sobre a seca.

\section{Aspectos históricos e ciclos econômicos}

No questionário aplicado, a seguinte pergunta foi feita: Quais recursos naturais são utilizados para o sustento e trabalho na região? Entre os 14 respondentes, 11 citaram a cana-de-açúcar e 
produção de rapadura, sendo o tipo de resposta mais incidente, exemplificada com a resposta escrita abaixo:

\begin{abstract}
A principal fonte de recursos de nossa região é a cultura de cana-de-açúcar que é plantada especificamente nas áreas do brejo, em que as terras têm umidade necessária para seu desenvolvimento e de onde se faz rapadura, a cachaça, doces e outros. Ainda temos uma pequena parte de extrativismo de algumas plantas que são típicas da região ou ajudam no sustento da familia.
\end{abstract}

Todas as questões foram dialogadas com a turma e pudemos discutir um pouco da influência histórica nos ciclos econômicos e culturais da região. A cana-de-açúcar foi introduzida no sertão no século XVII, o que agregou importância econômica à região até o século XIX e, ainda hoje, permanece fortemente na região semiárida, considerada uma das maiores fontes de renda. Além da questão econômica, o produto compõe as tradições culturais locais, pois as pessoas da comunidade de Brejo dos Olhos d`Água consideram que possuem a melhor rapadura de toda a região.

Como já exposto, a caatinga não é homogênea e contém locais mais úmidos, como os brejos de pé de serra, que é caso da comunidade de Brejo dos Olhos d'água. Estes locais eram os refúgios indígenas nos períodos de seca mais acentuada e "logo que os colonizadores descobriram as potencialidades das serras úmidas - posteriormente designadas brejos - houve uma rápida investida para a conquista desses espaços distribuídos nos imensos sertões" (AB'SABER, 2007 , p. 98). Estes brejos, além de produzirem os alimentos de subsistência, deram origem aos pequenos engenhos para produção de rapadura, dentro do ciclo da principal plantação tropical da época como se observa nas seguintes imagens. Esta cultura possui tal relevância que entre as 61 fotografias feitas, pelos quatro grupos de trabalho formados, 21 retrataram a plantação da cana e os engenhos de rapadura, como se exemplifica na Figura 1.

Figura 1. Fotos 1A; 1B: Engenho de cana-de-açúcar. Foto 1C: Plantação de cana-de-açúcar.
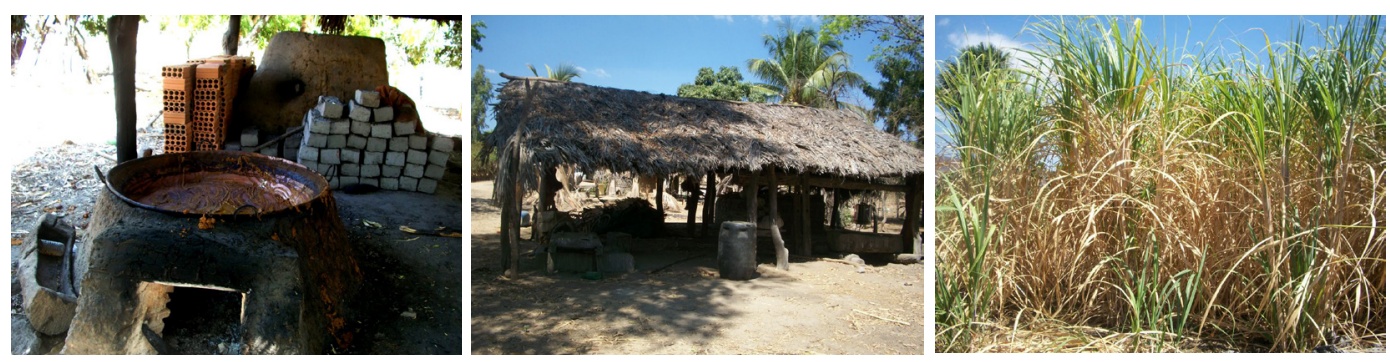

Fonte: imagens captadas pela turma participante da pesquisa (Grupo 1). 
Outras escolhas nos modos de vida adotados, também se originaram há muito tempo. Durante a colonização, com o sertão nordestino habitado por índios, destaca-se alguns aspectos durante a ocupação portuguesa. Na primeira metade do século XVI, os colonizadores trouxeram para o Brasil o gado, cuja criação inicial ocorreu nas fazendas litorâneas, onde se concentrava a ocupação. Com a invasão holandesa, no início do século XVII, criadores temerosos que os invasores requisitassem seus animais, seguiram com seus rebanhos para o interior dos estados nordestinos, usando como principal eixo condutor o Rio São Francisco, atingindo, assim, o semiárido (ANDRADE, 2004).

Segundo Ab’Saber (2007), ao findar o século XVII (entre 1695-1780) se inicia o deslanche do ciclo do ouro. Isso causou um apossamento fragmentário, porém generalizado de todos os sertões, incorporando como mão de obra escrava os índios e os negros, nas atividades de pastoreio. Iniciou-se, assim, o processo de miscigenação, responsável pela formação da população cabocla. De acordo com Andrade (2004, p. 48-49), “a descoberta do ouro nas Gerais e a formação de um grande adensamento populacional em área distante do litoral trouxeram grandes vantagens para os criadores de gado do sertão que passaram a abastecer os grandes centros de mineração".

Podemos destacar, portanto, a influência da invasão holandesa e a correlação direta entre a ocupação territorial e os ciclos econômicos vividos no Brasil, nos quais os ciclos do gado, da cana-de-açúcar e do ouro marcam a ocupação colonizadora do semiárido nordestino.

\section{Aspectos políticos}

A outra pergunta formulada no questionário aplicado foi: Você acha possivel ter uma vida sustentável em sua região levando em consideração a sobrevivência das pessoas e a manutenção do meio ambiente? Para que isso possa acontecer, o que é necessário?

Primeiramente, observamos através das respostas que, embora a pergunta tenha sido direcionada para a sustentabilidade em seu sentido amplo, ela foi compreendida por praticamente todas/os as/os participantes na perspectiva do seu próprio sustento - a manutenção de suas existências, porque essa questão ocupa lugar central em suas vidas. Destacamos as seguintes respostas:

Sim, épossivel, pois as famílias recebem vários auxilios do governo como: bolsa família, cartão verde, além de receberem uma aposentadoria. Em relação à manutenção ao meio ambiente, as autoridades competentes deveriam estar mais presentes nas comunidades e dialogar com mais palestras e educando melhor as comunidades.

Tem pessoas que tem aqui vivendo exclusivamente dos beneficios [do governo], porque plantou a lavoura e não deu.

Os beneficios [do governo] ajudam bastante. Trabalho aqui não é suficiente.

Cumprindo o propósito educativo do curso, apresentamos o conceito de sustentabilidade que se baseia no tripé economia, sociedade e meio ambiente e, a partir do entendimento que apresentaram, trouxemos a questão do sustento das pessoas, englobando os aspectos sociais e econômicos. Incluímos a esfera ambiental e os limites dos recursos naturais. 
Percebemos que a comunidade tem costumes herdados que são pouco viáveis ambientalmente, tais como a prevalência do plantio de cana e sua colheita usando o fogo, o que acaba afetando e empobrecendo o solo, além de ser potencial causa de problemas de saúde. Ao trabalharmos e discutirmos estas questões sob a ótica socioambiental, as pessoas puderam repensar suas práticas, tornando-se intérpretes e conhecedoras de suas histórias para decidirem ações futuras. A partir das respostas citadas, exemplificadas anteriormente, também foi possível dialogar com a turma, alguns aspectos políticos que permeiam a relação com o semiárido, como a dependência histórica de sua população dos auxílios governamentais e sobre a herança de políticas paternalistas que sempre permearam a região. Também é possível observar no primeiro exemplo de resposta, a necessidade de uma maior interação entre o governo e a comunidade, ou seja, as pessoas querem sentir a presença do governo próximo a sua localidade e transferem a responsabilidade da atuação ambiental para as "autoridades".

Entender a seca em seu contexto político é analisar, entre outros fatores, que a formação social do sertão se constituiu em bases de poder hierárquicas e do fazer político coronelista. Como descreve Lima (2010, p. 153), isto acabou "contribuindo definitivamente para a implementação de uma cultura política baseada na submissão, no comodismo, no paternalismo e no clientelismo". A localização desse bioma no nordeste brasileiro, distante dos centros de decisão política e, visto como um local de pouca produção econômica, contribuiu para a falta de interesse de investimentos e de políticas públicas para o semiárido. As poucas intervenções que foram feitas, eram baseadas na lógica que ficou conhecida como "indústria da seca", sendo caracterizada pelos desvios de verbas destinadas a obras de infraestrutura no semiárido para outros fins, em geral, particulares. Isso acabou por constituir pequenos núcleos de poder pautados na aquisição e posse de terras.

Diferente da realidade físico-material, a seca enquanto imagem, símbolo e representação, em qualquer de suas modalidades, é permeada por interesses políticos que geraram um discurso competente e autorizado que a encastela e a institucionaliza (GOMES, 1998). Corroborando com esse entendimento, Martins (2006, p. 64-65) afirma que:

[...] as secas são também humanamente e culturalmente produzidas, seja pelas formas de capitalização das secas em benefício das oligarquias locais, seja pelo fato de que não houve o desenvolvimento de atitudes e de aparatos técnicos que permitissem uma convivência instruída e preventiva em relação a elas.

As políticas públicas formuladas para o semiárido, como a criação do Grupo de Trabalho do Desenvolvimento do Nordeste (GTDN), que se desdobra posteriormente na Superintendência do Desenvolvimento do Nordeste (SUDENE), também não contribuíram para mudar os preconceitos que existem sobre o semiárido e para trazer autonomia ao seu povo, mantendo a lógica economicista e das políticas de "combate à seca". De acordo com Gomes (1998, p. 73), a concepção da seca segundo o GTDN é de "um fenômeno natural, que ganha força e eleva-se a cataclisma econômico-social, por encontrar uma economia inapta e vulnerável". Portanto, o GTDN, além de não considerar a historicidade da seca, mantém a visão de uma economia improdutiva, que inclui inaptidão para a agricultura e a criação de animais, reforçando o estereótipo de solo pobre e de uma população "vítima" de suas circunstâncias naturais. 
Segundo a comunidade de Brejo dos Olhos d'água, o auxílio governamental, atualmente, garante a sobrevivência de muitas famílias locais. Porém, é sempre importante refletir se as políticas empregadas estão gerando condições de autonomia para seus habitantes ou se estes continuarão dependentes de auxílios governamentais até que políticas públicas sejam formuladas e implementadas para melhorarem a infraestrutura de fato, proporcionando formação escolar e profissional adequada e condições dignas de vida.

\section{Aspectos culturais e religiosos}

Os aspectos culturais vivenciados no semiárido têm forte entrelaçamento com os aspectos descritos anteriormente. Por exemplo, a produção e o consumo de rapadura e cachaça são considerados aspectos culturais da região, que possui vários engenhos de cana-de-açúcar e tem grande parte de suas terras ocupadas com a plantação da cana. Como destacamos anteriormente, a introdução desta cultura tropical respondeu tanto ao ciclo econômico vivido no Brasil como um todo, como a apropriação das terras úmidas do semiárido.

Já em relação às práticas religiosas, apesar do crescimento recente de igrejas evangélicas na região, é a igreja católica que ainda predomina, desde a fundação do município de Barra por franciscanos, em 1670. A força que a explicação divina tem no sertão pode ser entendida por duas esferas. Uma é pelo abandono social e político, que abriu espaço para que padres e bispos católicos tivessem grande reconhecimento, tornando-se benfeitores comunitários. Na região da comunidade de Brejo dos Olhos d’Água e na sede do município em Barra, até cerca de 30 anos atrás, este foi um cenário comum, relatado através na seguinte fala, transcrita a partir de um dos diálogos com a turma: "o Bispo Dom João Munizé é um marco para a cidade e foi o primeiro a se preocupar em fazer uma casa [com função social]. Vendeu ouro e peças da igreja para isso".

Desta forma, a comunidade de Brejo dos Olhos d'água mantém até hoje os festejos católicos, quermesses e os consideram tanto como aspecto cultural, como religioso. Entre as professoras/es ainda existe a concepção da explicação da seca, pelo aspecto divino e religioso, quando expressam que "a chuva é vontade de Deus, bem como a seca" e "[...] morar na caatinga já é um recurso natural e gratificante para quem nasce e cresce trabalhando e orando por chuva". Portanto, ao se considerar a historicidade na formação cultural e religiosa desta comunidade, percebe-se a agregação de valores católicos através do convívio com padres e bispos que supriram necessidades sociais que o poder público não atendia. E, no aspecto mais profundo, a transcendência espiritual, na busca de conforto durante o sofrimento aos quais são expostos.

Gomes (1998), que em sua pesquisa investigou as explicações da seca pela ótica de moradores sertanejos, constatou que $52 \%$ deles possuem uma concepção mágico-religiosa do fenômeno. Segundo o autor, que criou categorias de explicação da seca, a mágico-religiosa compreende "todas as formas de pensamento e crenças, rituais e imagens nas quais os sertanejos atribuem a figuras divinas o desencadeamento das secas. Ou seja, aquelas representações e ações que tornam Deus ou outras entidades divinas como causa primeira de tudo" (GOMES, 1998, p. 100). Este autor observou também que tanto a imagem do sertanejo sofredor, por ser pecador e, assim, merecedor do sofrer, como a do sertanejo herói por suportar e sobreviver à seca, estão presentes na representação religiosa destas comunidades e considera que o imaginário religioso é uma decorrência direta da pobreza: 
[...] a realidade de privação em que vivem os grupos é reciprocamente contígua à imaginação religiosa. A seca, enquanto significação imaginária, fornece ao espírito privado e necessitado a urgência do contato com a entidade divina; fornece, enfim, a cristalização do suplício e a realimentação necessária das crenças religiosas, periodicamente (GOMES, 1998, p. 131).

Desta maneira, além da presença católica no semiárido influenciar a constituição do pensamento mágico-religioso, podemos compreender que o desamparo social e político é tanto que divinizar a seca pode ser confortante. Porém, ao mesmo tempo, retira de seus habitantes a expectativa de contribuírem para a resolução de seus problemas, bem como desloca o entendimento da responsabilidade das esferas políticas e sociais, uma vez que, nesta lógica, se a seca independe da vontade dos seres humanos não há nada a ser feito.

\section{Aspectos socioambientais}

Entre todas as imagens feitas para representar os aspectos socioambientais destacamos as duas demonstradas na Figura 2. A foto 2A foi apresentada pela turma como a mais representativa da realidade local, pois contém os buritis, uma planta nativa, e a cana, representante dos hábitos culturais e comerciais da comunidade. O grupo foi, então, questionado sobre o que representaria a mulher presente na imagem e as respostas foram "nosso povo sofrido" e "o povo nordestino". Questionados novamente sobre o porquê desse sofrimento, especificamente em relação à senhora, ao que responderam que é devido ao fato dela trabalhar na roça e precisar controlar a irrigação para que não morra tudo.

Figura 2. Foto 2A: Dona de terreno; Foto 2B: Riacho seco
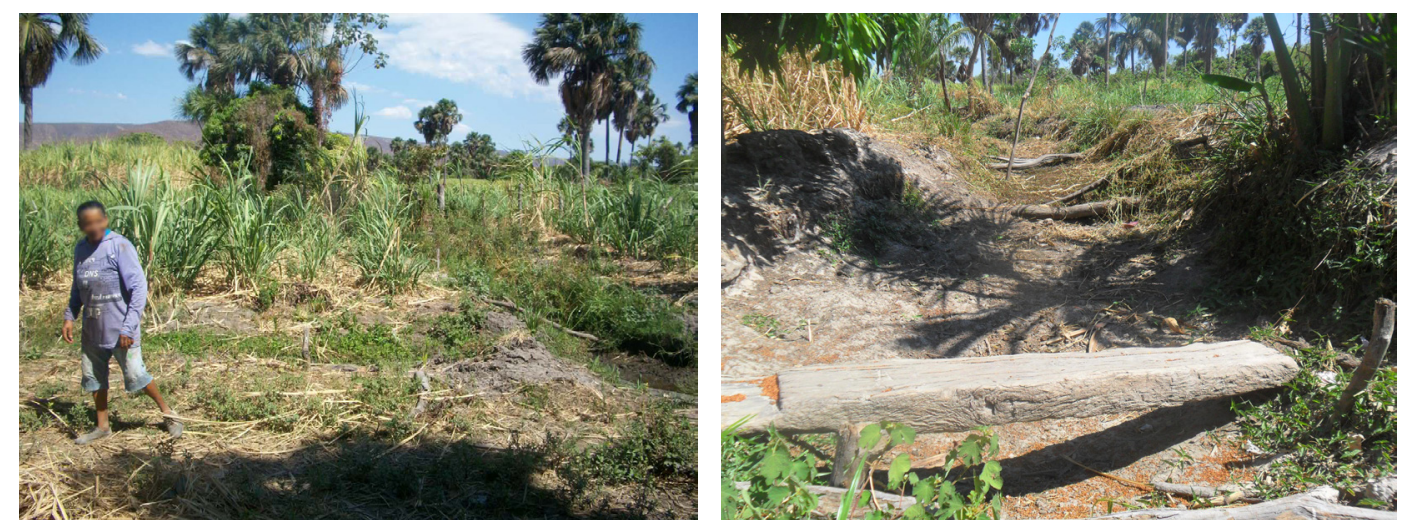

Fonte: imagens captadas pela turma participante da pesquisa (Grupo 1). 
Ao estender a discussão para toda a turma, questionamos se era possível dizer que esta imagem poderia representar o povo nordestino e as respostas foram todas afirmativas com as seguintes justificativas, transcritas posteriormente: "Ela planta, faz rapadura, borda" e "Ai tá a imagem. Ai é a característica do nordestino, do sofredor".

Analisando esse dado e procurando interpretar seus sentidos, percebemos que o nordestino sofredor pode remeter ao eu sofredor. Dada a importância da temática, esse assunto foi discutido durante um tempo maior com o grupo. Preliminarmente, o fato das pessoas se sentirem sofredoras, terem dificuldade no cultivo de suas culturas e na reprodução de seus modos de vida, justificaria a utilização dos recursos naturais sem planejamento, como também foi constatado por Drumond (2004).

A discussão foi estendida em relação aos aspectos da seca e a percepção da turma sobre a influência antrópica nos processos que levam a escassez da água, como demonstrado na foto 2B. As pessoas consideram que houve agravamento da seca nos últimos dez anos e apontam como motivo o cultivo da cana, que faz uso de queimadas, e o desmatamento, o que atribuem aos costumes dos produtores locais herdados dos seus antepassados. Existe, portanto, uma contradição, pois ao mesmo tempo em que a condição de sofrimento pode justificar a utilização irracional dos recursos para a sobrevivência, há o entendimento sobre as heranças e influências humanas no agravamento da seca.

Tantos foram os apontamentos levantados nesta discussão que, no encontro seguinte, formulamos uma questão sobre as dificuldades da vida na caatinga. Esta questão foi respondida por 21 participantes e posteriormente discutida com a turma no formato de grupo focal. A questão indagava: Porque as pessoas que moram na caatinga são um "povo sofrido"? Quais são as maiores dificuldades? Você considera que épior morar na caatinga do que em outros biomas brasileiros?

A totalidade das respostas foi afirmativa em confirmar o sofrimento de viver na caatinga, entretanto, não foi unanimidade que é pior morar na caatinga do que em outros biomas, posição defendida por cinco participantes. Em relação aos motivos de sofrimento, destacaram-se as questões do cultivo dos alimentos, do convívio com a seca, do trabalho duro, exemplificando-se através de algumas respostas:

As pessoas que moram na caatinga são gente sofrida por causa do trabalho que épesado e um modo de vida mais escasso, onde a maior dificuldade é a água.

Morar na caatinga é certamente muito mais difícil [...] infelizmente a disponibilidade de água é escassa, ocasionando uma série de dificuldades para o povo que vive na região, que vai desde a dificuldade em praticar a agricultura e a pecuária, até a obtenção desse líquido para satisfazer suas necessidades diárias.

Porque são pessoas que não tem oportunidade. As maiores dificuldades são no meu ponto de vista, a falta de comunicaşão, de transporte, a seca e outras [...].

Os nordestinos são sofridos por natureza. As dificuldades do povo da caatinga são: condições de vida precária tendo em vista a saúde, moradia, alimentação. Creio que morar na caatinga é um sacrificio, mas vale a pena valorizar o lugar que vive. 
Porque o trabalho braçal é de sol a sol [...].

Sim, pois as maiores dificuldades é a falta de alimento, pouca chuva para a produção desses alimentos e a pouca assistência governamental.

Pelo fato de viver em regiões menos favorecidas pelo poder público, pela falta de chuva, o indice de pessoas semianalfabeta, sem falar na questão de habitação. Por isso se torna a pior região para morar.

Devido a seca, as condições de moradia, trabalho, atenção a saúde, educação, etc. Eu acredito que morar na região da caatinga é um desafio para os povos.

Entre todas as respostas, apenas três remeteram aos aspectos sociais e somente duas, incluíram a responsabilidade governamental pelo que se vive no semiárido. As outras respostas revelaram a percepção das dificuldades de vida decorrentes das condições naturais da seca. Resultados parecidos foram apontados no trabalho de Gomes (1998).

Durante a saída fotográfica, a água e as questões que permeiam a seca foram os aspectos mais retratados, se comparado às outras temáticas, sendo tema de 23 entre as 61 fotografias feitas pelos quatro grupos, conforme se exemplifica na Figura 3. A água é realmente um elemento muito forte na relação entre os seres humanos com o meio ambiente (MARIN; OLIVEIRA; COMAR, 2003) e, no sertão, tem ainda mais força. Segundo Gomes (1998, p. 57) "a seca assume uma significação tal para o homem que habita o espaço demarcado como semiárido nordestino, que é difícil prever sua importância”.

Figura 3. Representações da seca/água (Fotos 3A; 3D: Brejos. Foto 3B: Gado. Foto 3C: Peixe Corró)
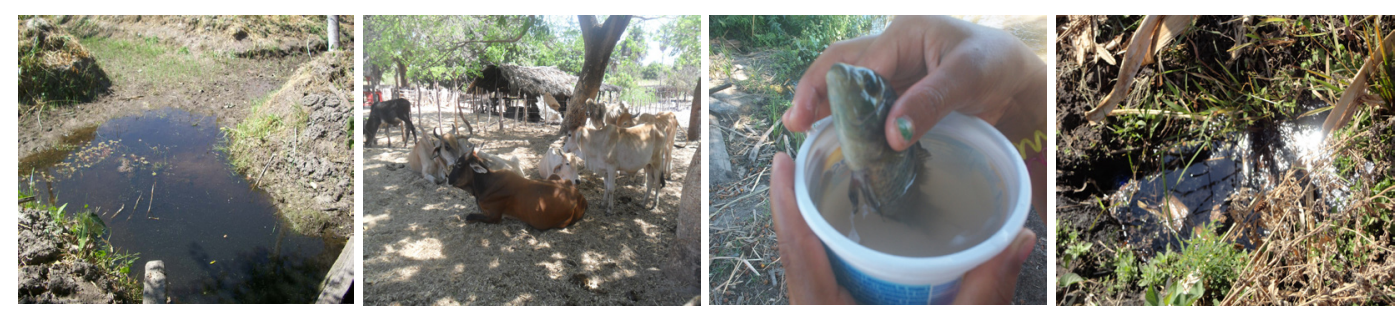

Fonte: imagens captadas pela turma participante da pesquisa (Grupos 1, 2, 3, 4).

As fotos 3A e 3D retratam a água diretamente, em uma forma comum de se encontrá-la na comunidade, que são brejos e as pequenas poças. Este é o motivo da comunidade chamar-se Brejo dos Olhos d'Água. As outras duas fotografias representam a água através do gado e do peixe aspectos que para as/os autoras/es, também a definem. Na discussão da foto $3 \mathrm{C}$, mos- 
trando um peixe que é usado para alimentação, o foco inicial da descrição foi a água. Porém, $\operatorname{logo}$ as falas se converteram na preocupação com seu esgotamento e com a seca.

A foto 3B, que foi feita demonstrando o gado magro, reflete a questão da seca para o grupo que a retratou. Cabe ressaltar esta influência da mídia, dos materiais didáticos e dos discursos autorizados, por quem detêm os meios comunicativos, na consolidação do gado magro enquanto símbolo da seca, como já descrito nos aspectos históricos. Assim, este grupo escolheu representar a seca do mesmo modo que, por exemplo, as mídias televisivas usam como representação dos infortúnios da seca nordestina há anos. Como descreve Andrade (1985), a ocupação de terras do semiárido não se ateve ao planejamento e escolha das espécies propícias às suas condições climáticas. Assim, houve a introdução do gado e o cultivo da cana-de-açúcar e algodão, espécies bem-sucedidas na porção litorânea úmida. Estas culturas introduzidas eram social e ambientalmente inadequadas à região, exigindo altos custos para a produção e beneficiando populações que viviam distantes.

Dados do Instituto Regional da Pequena Agropecuária Apropriada (2001) comparam a criação bovina com a caprina e os resultados são claros em demonstrar qual dos animais é mais propício ao semiárido. Uma vaca tem a necessidade alimentícia comparada a de oito cabras, que juntas precisam de 48 litros de água, enquanto uma única vaca necessita de 53 litros por dia, além da quantidade de crias da cabra ser muito superior e ter outras vantagens comparativas à região semiárida. Porém, não se superou os hábitos deixados pelos colonizadores e a ilusão do maior valor econômico, o que não se concretiza quando se somam os custos de manutenção destes animais e as perdas que ocorrem com secas acentuadas.

\section{Aspectos educacionais}

A falta de identificação com os livros didáticos se evidenciou, nesta pesquisa, quando após a prática fotográfica, avaliamos a atividade e questionamos: Vocês acham que a imagens dos livros didáticos são boas para representar o contexto de vocês? As seguintes respostas transcritas demonstram a percepção que as/os professoras/es têm do contexto do semiárido não está representado nestes livros: "em livros didáticos a nossa realidade não é representada" e "os meninos desses livros são todos loiros".

Não nos aprofundamos na avaliação dos materiais didáticos utilizados, porém constatamos que a prática fotográfica, neste sentido, pode ser um importante instrumento didático. As/os professoras/es ao fazerem suas próprias fotografias podem ilustrar com propriedade o que querem discutir em suas realidades. Na medida do possível e do acesso aos equipamentos podem também solicitar que suas/seus estudantes façam o mesmo, criando formas de facilitar a apresentação da identidade local e discutindo temas que se evidenciarem na tomada de fotografias para discussão e constituição de um pensamento crítico e analítico.

Existem diferentes aspectos educacionais que afetam a caatinga, sendo que nem todos são exclusivos ao bioma. Observa-se, especificamente, em relação ao semiárido que durante muito tempo as universidades e as pesquisas se concentraram em territórios próximos ao litoral, relacionado à localização das capitais. A produção de seu saber, apesar de ser crescente, ainda possui muitas lacunas. Barbosa, Silva e Nascimento (2011, p. 404) afirmam:

[...] até recentemente, cerca de $90 \%$ dos doutores ligados aos programas de pós-graduação acadêmicos estavam concentrados nessa faixa [litorânea]. 
Essa situação tem mudado gradativamente nos últimos anos [...]. Este abandono acadêmico se reflete em diversas áreas a falta de conhecimentos sobre a biodiversidade e dos seus potenciais naturais e a falta de desenvolvimento de tecnologias apropriadas à região implicam diretamente na manutenção do "combate à seca" ao invés da "convivência com a seca".

Outra questão, que recai sobre o semiárido, é a produção de materiais didáticos e a da mídia. Editoras, grandes emissoras, jornais de relevância nacional também se localizam em grandes centros urbanos, principalmente no Sudeste, distante da realidade da caatinga e reproduzem imagens e discursos preconceituosos, como descreve Reis (2010, p. 112):

[...] a imprensa nacional e os que escreveram sobre esta região, tendo como parâmetros apenas uma época do ano, ou apenas um ângulo da região, não perceberam a sua complexidade do Semiárido Brasileiro. Os livros didáticos que circulam na nossa região reforçam essa imagem negativa da região, do sujeito que vive no Semiárido [...]. É essa a negatividade que se criou do Semiárido Brasileiro e que ainda está presente entre nós e que terminamos por assumi-la e proliferá-la.

A mídia e os materiais didáticos que chegam até e escola e a forma como as/os professoras/es concebem o semiárido, são fatores que, muitas vezes, não colaboram para o rompimento destas visões estereotipadas. Portanto, o último ponto que apontamos em relação à educação é a necessidade de uma formação permanente e continuada de professoras/es, como prevê a Lei de Diretrizes e Bases da Educação (LDB). Lima (2010, p. 153) suscita a importância do currículo escolar na definição dos sujeitos e no modelo de sociedade que se constrói, declarando que:

[...] o fato de as escolas incorporarem em seu currículo representações que caracterizam as pessoas dessa região como "coitadinhas", "pobrezinhas", “incultas”, construindo caricaturas e estereótipos de sertanejo carregados de preconceito, merece uma análise cuidadosa. Essa pode ser uma estratégia de neutralização das pessoas pela inferiorização de sua cultura.

Esse quadro se agrava no semiárido pela falta de corpo docente suficiente e de infraestrutura necessária. Assim, a responsabilidade maior da educação recai sobre as/os professoras / es que, se não forem críticos e autônomos para produzirem um saber contextualizado, podem utilizar discursos e materiais didáticos distantes de suas realidades o que dificulta o rompimento do estereótipo negativo da/o sertaneja/o.

\section{Considerações finais}

Pudemos observar que a coleta de dados atrelada à formação de professoras/es foi um rico processo que proporcionou um ambiente propício aos dados emergirem em diferentes momentos do processo formativo. Acreditamos que o trabalho cumpriu um importante papel 
social de aproximação entre a academia e a comunidade. As raízes da construção dos olhares sobre a seca possuem uma longa trajetória, cujo rompimento e superação não será simples, pois qualquer mudança de concepção não acontece instantaneamente. Muitas influências se incorporaram à cultura catingueira, o que exige um cuidado para que uma (des)construção dos olhares sobre a seca não seja mais um processo autoritário e sim um convite para a reflexão sobre a complexidade destes fatores e sua influência na constituição da identidade dos sujeitos envolvidos, bem como a escolha de caminhos a serem trilhados. Entendemos que é importante colocar em foco o estigma negativo do semiárido baiano, da caatinga e da seca, e que a educação pode colaborar para essa transformação, desde que contextualizada, historicizada e considerando a complexidade dos fatores elencados. Especificamente com o grupo participante desta pesquisa, embora não possamos precisar exatamente o grau de mudança em sua forma de se ver e se colocar no mundo, a formação foi uma oportunidade de juntos e juntas refletirmos e dialogarmos sobre o tema. Desta forma, abriu-se a possibilidade para novas reflexões, olhares e atitudes, seguindo a premissa de que somos indivíduos que aprendem e ensinam. A educação é um continuum e está impregnada de diversos fatores sociais que se imbricam e ao mesmo tempo extrapolam qualquer processo de aprendizagem. Para tanto, sugerimos que os aspectos descritos nesta pesquisa possam ser considerados durante os processos de formação de professoras/es que atuem no semiárido, pois podem colaborar para o entendimento do cenário que compõe a percepção sobre a seca nordestina. É importante trabalhar a educação em uma perspectiva que reafirme as questões históricas, políticas e socioambientais da seca e investir em novos olhares de valorização deste bioma que é exclusivamente brasileiro. Os dados confirmam a necessidade da formação continuada de professoras/es, pois boa parte ainda traz visões estereotipadas sobre a seca e reproduzem discursos difundidos ao longo da história. Desta forma, a formação de sujeitos críticos e atuantes nas suas realidades pode contribuir para um melhor desenvolvimento da região semiárida e de suas/seus habitantes dentro de suas potencialidades.

\section{Referências}

AB'SABER, A. N. Os domínios de natureza no Brasil: potencialidades paisagísticas. 4. ed. São Paulo: Ateliê Editorial, 2007.

ANDRADE, M. C. Nordeste: alternativas da agricultura. Campinas: Papirus, 1988. . A questão do território no Brasil. 2. ed. São Paulo: Hucitec, 2004.

A seca: realidade e mito. Recife: ASA, 1985.

BARBOSA, J. E. L.; SILVA, M. M. P.; NASCIMENTO, D. G. E. G. Educação ambiental e desenvolvimento sustentável no semiárido. In: ABÍLIO, F. J. P. (Org). Educação ambiental para o semiárido. João Pessoa: Editora Universitária da UFPB, 2011. p. 386-418.

BANKS, M. Dados visuais para pesquisa qualitativa. Porto Alegre: Artmed, 2009.

CARVALHO, I. C. M. Educação ambiental: a formação do sujeito ecológico. 4. ed. São Paulo: Cortez, 2008. 
CASTELLETTI, C. H. M. et al. Quanto ainda resta da caatinga?: uma estimativa preliminar. In: LEAL, I. R.; TABARELLI, M.; SILVA, J. M. C. (Org.). Ecologia e conservação da caatinga. Recife: Ed. Universitária da UFPE, 2003. p. 719-734.

DRUMOND, M. A. et al. Estratégias para o uso sustentável da biodiversidade da caatinga. In: SILVA, J. M. C. et al. (Org.). Biodiversidade da caatinga: áreas e ações prioritárias para a conservação. Brasilia: Ministério do Meio Ambiente, 2004. p. 329-340.

FARNSWORTH, B. E. Conservation photography as environmental education: focus on the pedagogues. Environmental Education Research, Abingdon, v. 17, n. 6, p. 769-787, 2011.

FLICK, U. Introdução à pesquisa qualitativa. 3. ed. Porto Alegre: Artmed, 2009.

FREIRE, P. Pedagogia da autonomia. 27. ed. Rio de Janeiro: Paz e Terra, 2003.

. À sombra desta mangueira. 10. ed. Rio de Janeiro: Civilização Brasileira, 2012.

GADAMAER, H-G. Hermenêutica em retrospectiva. 2. ed. Petrópolis: Vozes, 2012.

GOMES, A. M. Imaginário social da seca. Recife: Massangana, 1998.

GODOY, A. S. Introdução à pesquisa qualitativa e suas possibilidades. Revista de

Administração de Empresas, São Paulo, v. 35, n. 2, p. 57-63, 1995. Disponível em:

<http://dx.doi.org/10.1590/S0034-75901995000200008>. Acesso em: 18 jun. 2016.

HERMANN, N. Hermenêutica e educação. Rio de Janeiro: DP\&A, 2002.

HOFSTATTER, L. J. V. O imagético de uma comunidade caatingueira e os sentidos atribuídos à onça em um processo formativo de educação ambiental crítica. 2013. 199 f. Dissertação (Mestrado em Ciências) - Universidade Federal de São Carlos, São Carlos, 2013.

IARED, V. G.; DI TULLIO, A.; OLIVEIRA, H. T. Impressões de educadoras/es ambientais em relação a visitas guiadas em um zoológico. REMEA: revista eletrônica do mestrado em educação ambiental, Rio Grande, v. 28, p. 258-273, 2012. Disponível em: < http:// repositorio.furg.br/handle/1/3840>. Acesso em: 18 jun. 2016.

INSTITUTO BRASILEIRO DE GEOGRAFIA E ESTATISTICA. Censo demográfico 2010. Disponível em: <http://www.ibge.gov.br/home/estatistica/populacao/censo2010/>. Acesso em: 2 nov. 2012.

INSTITUTO REGIONAL DA PEQUENA AGROPECUÁRIA APROPRIADA. Cabras e ovelhas: a criação no sertão. Juazeiro: IRPAA, 2001.

LABURÚ, C. E.; ARRUDA, S. M.; NARDI, R. Pluralismo metodológico no ensino de ciências. Ciência e Educação, Bauru, v. 9, n. 2, p. 247-260, 2003. Disponível em: < http:/ / dx.doi.org/10.1590/S1516-73132003000200007>. Acesso em: 18 jun. 2016.

LIMA, E. S. O currículo como espaço de diálogo entre as diversidades socioculturais do semiárido. In: SILVA, C. M. S. et al. (Org.). Semiárido piauiense: educação e contexto. Campina Grande: Triunfal, 2010. p. 151-172. 
MARIN, A. A.; OLIVEIRA, H. T.; COMAR, V. Percepción ambiental, imaginario y prácticas educativas. Tópicos en Educación Ambiental, Mexico, v. 5, n. 13, p. 73-80, 2003. Disponível em: <http://www.anea.org.mx/wp-content/uploads/2015/02/Paginas-7380-n13.pdf>. Acesso em: 18 jun. 2016.

MARTINS, J. S. Anotações em torno do conceito de educação para a convivência com o semi-árido. In: REDE DE EDUCACÃO DO SEMI-ÁRIDO BRASILEIRO. Educação para a convivência com o semi-árido: reflexões teórico-práticas. Juazeiro: Editorial RESAB, 2006. p. 45-84.

OLIVEIRA, M. M. Como fazer pesquisa qualitativa. Petrópolis: Vozes, 2007.

OLIVEIRA, H. T.; ZANCUL, M. C. S. Interdisciplinaridade, transdisciplinaridade e transversalidade na educação ambiental: da compreensão dos conceitos à incorporação prática por meio da pedagogia de projetos. In: OLIVEIRA, H. T. et al. (Org.). Cadernos do Cescar, educação ambiental, caderno 1: os fundamentos e as políticas públicas de educação ambiental na constituição do coletivo educador de São Carlos, Araraquara, Jaboticabal e região. São Carlos: Futura, 2011. p. 58-69.

OLIVEIRA, H. T. et al. Educação ambiental na formação inicial de professores. In: REUNIÃO ANUAL DA ANPED, 23., 2000, Caxambu. Disponível em: < http://23reuniao. anped.org.br/textos/0810p.PDF>. Acesso em: 14 maio 2013.

OLIVEIRA, H. T. Transdisciplinaridade. In: FERRARO JUNIOR, L.A. Encontros e caminhos: formação de educadoras(es) ambientais e coletivos educadores. Brasília: Diretoria de Educação Ambiental, 2005.

OLIVEIRA, H. T.; FARIAS, C. R. O.; PAVESI, A. Educação ambiental no ensino superior brasileiro: caminhos percorridos e perspectivas para políticas públicas. Revista Brasileira de Educação Ambiental, Brasília, n. 3, p. 109-112, 2008.

PENN, G. Análise semiótica de imagens paradas. In: BAUER, W. M.; GASKELL, G. (Org.). Pesquisa qualitativa com texto, imagem e som: um manual prático. 10. ed. Petrópolis: Vozes, 2010. p. 319-342.

REIS, E. S. Educação para a convivência com o semiárido: desafios e possibilidades. In: SILVA, C. M. S. et al. (Org.). Semiárido piauiense: educação e contexto. Campina Grande: Triunfal, 2010. p. 109-130.

SANTOS, A. Complexidade e transdisciplinaridade em educação: cinco princípios para resgatar o perdido. Revista Brasileira de Educação, Rio de Janeiro, v. 13, n. 37, p. 71-83, 2008. Disponível em: <http://dx.doi.org/10.1590/S1413-24782008000100007>. Acesso em: 18 jun. 2016.

SAUVÉ, L. Uma cartografia das correntes em educação ambiental. In: SATO, M.; CARVALHO, I. C. M. (Org.). Educação ambiental: pesquisa e desafios. Porto Alegre: Artmed, 2005. p. 17-44. 
SILVA, C. M. S.; SILVA J. P. O. A relação entre texto e contexto na perspectiva da educação para a convivência com o semiárido. In: SILVA, C. M. S. et al. (Org.). Semiárido piauiense: educação e contexto. Campina Grande: Triunfal, 2010. p. 215-228.

SORRENTINO, M. De Tbilissi a Thessalonik: a educação ambiental no Brasil. In: QUINTAS, J. S. (Org.). Pensando e praticando a educação ambiental no Brasil. Brasília: IBAMA, 2002. p. 107-118.

SOUSA SOBRINHO, J. Brejos da Barra-BA: comunidades camponesas no processo de desenvolvimento no Vale do São Francisco. 2006. 271 f. Dissertação (Mestrado em Geografia Humana) - Universidade de São Paulo, São Paulo, 2006.

TAVARES, C. Educação integral, educação contextualizada e educação em direitos humanos: reflexões sobre seus pontos de intersecção e seus desafios. Acta Scientiarum: human and social sciences, Maringá, v. 31, n. 2, p. 141-150, 2009.

THIESEN, J. S. A interdisciplinaridade como um movimento articulador no processo de ensino-aprendizagem. Revista Brasileira de Educação, Rio de Janeiro, v. 13, n. 39, p. 545-554, Set./Dez. 2008. 